\title{
Journal of astonishment - a tool to increase satisfaction with exchange programmes
}

\author{
Claus H. Reinhardt ${ }^{\mathrm{a} *}$ and Evelyne N. Rosen ${ }^{\mathrm{b}}$ \\ ${ }^{a}$ Department of Biology, Training College Cologne Claudiusstr, Cologne, Germany; \\ ${ }^{b}$ International Foreign Students Department, University Lille 3, Villeneuve d'Ascq cedex, France
}

(Received 25 February 2012; final version received 8 July 2012)

\begin{abstract}
Many medical students use exchange programmes to enrich their portfolio. However, such a confrontation with reality can be challenging because custom and practice sometimes differ radically between countries. Exchange students post specific peculiarities, as encountered by them abroad, onto the medical exchange website. They can ask for the community's help and are expected to describe the (preliminary) solution that they have found. The "journal of astonishment" is structured by country and is designed not only to provide help for current exchange students but also to prepare future students for their stay abroad. Upon conclusion of the exchange, its satisfaction to both student and host institution is evaluated. Following the intervention, non-illness related drop out rates decreased by nearly $30 \%$ and student satisfaction improved by 1.7 points on a 10-point satisfaction scale. Host academic institution satisfaction also increased. Postings from the community were considered helpful. Female students especially benefited from the exchange website when preparing for their exchange. The journal of astonishment thus helps students better to select and prepare for an exchange with a particular academic institution. Moreover, the interactive web-based platform can provide spontaneous assistance with problem handling. The journal of astonishment is a low-cost tool that enhances student and host academic institution satisfaction.
\end{abstract}

Keywords: confronting reality; problem solving; addressing institutional problems; moving learners

\section{Introduction}

Many aspects of university teaching and learning have become virtual. Most universities use learning platforms and there are blended learning concepts and computer-assisted assessment forms (Hall et al. 2012). However, there is still at least one aspect for highly successful studies which cannot yet be completed virtually, a stay abroad (Byram 2008). Many students report how fascinating this confrontation with a foreign culture has been, but some complain of having encountered insurmountable problems forcing some of them to terminate their stay prematurely (Reinhardt 2009).

At the same time, most academic host institutions are content with their exchange students. Some, however, complain about students who do not comply with their standards.

\footnotetext{
*Corresponding author. Email: drcreinhar@aol.com
} 
We asked our exchange students what the causes of their problems were: The most frequently delivered answer was that they had a false impression of what the exchange and the exchange university would be like.

Additionally, there were many differences that could cause problems at all stages of the stay (Murphy-Lejeune 2008). Examples from the planning stage include: to whom to address the letter of motivation; which institution eventually can host the exchange so that it will be recognised by the sending university; and the way housing is organised and the nature and standards of accommodation are. Once abroad new problems arise: who takes on responsibility for the exchange student; which academic institutions can offer help in the event of problems; and where such institutions are situated.

However, even if these basic fundamentals are managed there are still a lot of potential surprises to come. Many medical students go abroad during their compulsory internship. During this year they are expected to participate actively in the service: on the ward, in the emergency unit and the operating theatre. Even though there are global standards in medicine, procedures at home and abroad may well differ. For example, hands will always be disinfected before surgical interventions, but the means and steps of disinfection can vary. Insufficient disinfection is life threatening for patients. Therefore, local rules of disinfection have to be obeyed strictly. An exchange student who is to participate in a surgical intervention and who is not familiar with the local disinfection procedure can seriously endanger patients or at least delay the start of the intervention because in order to undergo a second procedure of disinfection. What a negative start of an exchange it would be if the operating professor has to wait for the exchange student to catch up with the disinfecting procedure! Depending on the (bad) temper of this professor some exchanges may never recover from this early mistake (Reinhardt 2009).

Moreover, there may be a wide range of tasks which an exchange student is expected to undertake. Some are expected to "shadow" an experienced doctor, others are expected to run the emergency unit alone with a doctor on call. But what makes it really difficult is that what is fine and challenging for one student who has a lot of experience because the student has worked as a nurse before, can be an excessive task for others who, prior to their exchange, focussed on research.

In addition, countries have different customs. Against the background of World War II, German students can sometimes experience hostility especially from elderly or intoxicated patients. Some exchange students have no problems in "sharing" these views, some are ready to pretend they come from a different country, some can successfully "hide" their nationality and finally for some this is unacceptable.

In some Roman Catholic countries, secular physicians have developed rather strange customs in the past to separate themselves from sisters. What can be exciting especially for certain male students can be completely unacceptable to female or students with committed religious views.

Thus there are many reasons why even high performance exchange-students can fail. Unfortunately the sort of information described above cannot be found in travel guides (Murphy-Lejeune 2008). Even former exchange students' (oral) reports can be misleading because of different inter-individual perceptions. 


\section{Approach}

In order to bridge this information gap we tried three different approaches over a period of one year. Each provided the specific information described above to exchange institutions for our medical exchange students. A total of 107 students were included.

Each approach was advertised over the intranet for medical students and during one compulsory lecture regarding internships. Due to varying previous response rates in the past, we asked students going abroad for a $100 €$ deposit until such time as they had posted their individual report or their journal of astonishment. Students who were not able to pay the deposit had to designate a faculty warrantor.

Upon conclusion of the exchange, the satisfaction of all students and all host institutions was evaluated.

\section{First approach: paper report}

Thirty-seven exchange students were asked to write a short report on their stay abroad. The printed reports were gathered in the student exchange bureau where they were held in readiness as Q\&A documents for consultation.

\section{Second approach: web-based report}

Thirty-nine exchange students were asked to write a short report on their stay, too. Once approval had been obtained, their written report was posted on the exchange website of the medical intranet. This exchange website could be consulted by all student members of the intranet.

\section{Third approach: "journal of astonishment blog"}

Thirty-one exchange students were asked to write a "journal of astonishment". The "journal of astonishment" is a tool from linguistic sciences. This journal focuses on what is different in the exchange institution when compared with in the sending institution (Develotte 2006). Moreover, the exchange students were asked how they handled the differences. These "journals of astonishment" were posted to a blog on the medical intranet. This pilot blog was created using the Mahara software. Mahara is open source software for ePortfolios. ${ }^{1}$ Mahara offered two major advantages. First this software can be integrated in Moodle. Second there are many ways of managing the access (Murphy 2011). A group for each exchange country was generated in Mahara. Exchange students were invited to post, as by them abroad, to the appropriate Mahara group. In addition to the second approach the web-blog offered to exchange students abroad the possibility to ask for the community's help with specific peculiarities encountered.

Future exchange students could access the blog in order to prepare for their stay. Moreover 6 months after return from their stay abroad the exchange institution was also granted access to the specific journal of astonishment.

One hundred and three exchange students were then asked to evaluate approaches 1-3. 


\section{Results}

More than $90 \%$ of students returned a suitable report or journal of astonishment. Return rates of each of the three approaches were comparable.

The overall number of evaluating students (103) was sufficient validly to compare satisfaction rates of each approach. Moreover, many host institutions were not present in all three approaches. Therefore, we present satisfaction rates and drop out rates in the form of a summary. Specific remarks for each approach are presented later in this article.

Since reports or "journals of astonishment" were provided, non-illness related drop out rates decreased considerably (by almost 30\%). The questionnaire revealed that overall satisfaction with the exchange increased by 1.7 points on a 10-point satisfaction scale. All students were grateful for this novel form of information gathering regardless of whether it came in the shape of paper reports, web-based reports or the "journal of astonishment" blog.

\section{Common remarks regarding the paper report and the web-based report}

As mentioned above, students were content with the reports in general. However, the specificity of the written reports was not conclusive. Even when it came to highly frequented exchange-institutions, students pointed out that essential information was missing.

\section{Specific remarks regarding the paper report}

Apart from the common remark mentioned above, students complained that during peak hours, future exchange students had to queue to consult the copies on display. Moreover, the exchange office staff protested that when copies got lost it was rather painstaking to produce new ones.

\section{Specific remarks regarding the web-based report}

Beyond the aforementioned remark, students were delighted about this form of presentation. They appreciated the fact that they could consult the website at home irrespective of the student exchange office's opening hours.

\section{Specific remarks regarding the journal of astonishment blog}

Students appreciated that in addition to the web-based report journals of astonishment focussed on peculiarities (rather than the choice of bars to visit). Moreover, students acknowledged the IT-possibility of asking the community for help. However, over $50 \%$ of those who asked for help stated that they either did not receive community help at all, or that the type of advice they did receive was not useful.

Six months after completion, additional individual blogs were made accessible to the respective host institution. More than $75 \%$ appreciated this unique chance to find out how their institution was perceived from an international student point of view. 


\section{Discussion}

The "journal of astonishment" offered several advantages over the other forms of reports stated above.

Most students preferred the focus on peculiarities. However, some students sadly missed non-specific information such as a hint towards the "in" bars, restaurants, etc. On the other hand, when we asked former exchange students how useful these non-specific information had been, many of them stated that tastes differ anyway and that many locations had changed over time. The technical possibility of asking the community for help as such is worthwhile. However, more than $50 \%$ of students stated that either no comment had been offered at all or that the comments given were not too helpful. The problems of the blog were that we did not have a significant number of bloggers overall and that for many institutions competent bloggers were not available. For these reasons we consider that we might in future issue a certificate which confirms participation in the blog which can form part of the individual student portfolio (Stefani, Mason, and Pegler 2007). We hope that this certificate might foster students to participate more. Moreover, we intend to encourage the faculty to enclose an obligatory paragraph in certificates for exchange students who come to our university stating whether they had participated in the blog.

Another solution could be to encourage several universities to create one common blog. However, in either case adequate technical support will be necessary. Even for our pilot blog, the loss of an enthusiastic and technically experienced student who served as administrator almost blocked the blog when important maintenance work on the faculty website was underway. This proves that sufficient funding is, as usual, a crucial point.

A further advantage of the blog was that we were able to use some of the medical problems encountered abroad as exercises in our regular medical courses (Hanson 2011): Learning teams of students had to compare the well known (to them) German procedure with the foreign one. They had to do literature research and analyse advantages, disadvantages and the crux of the matter. Apart from this exciting learning opportunity we hope that this procedure will advertise the exchange blog and will encourage more students to consider an exchange.

The fact that exchange universities were granted access to the relevant journal of astonishments 6 months after conclusion of the exchange was in most cases appreciated by the exchange universities. We chose this 6-month delay to ensure that students who criticised some peculiarities of practice or experience would know that they could not suffer from any retribution from the host institution.

Making the respective "journal of astonishment" accessible to the host institution implied that former exchange students had to translate their journals of astonishment into the local language or into English.

Moreover, we asked our students to give constructive and reflective feedback (Wetmore et al. 2010), even if they were less satisfied with their exchange. This work was in some aspects delicate, because on the one hand (and most importantly) we do not want to censor our students, but at the same time we do not want to offend exchange universities. We found two solutions to this problem: First we asked our students to write their journal for the exchange university in the first-personperspective only. Second in (one) case of important complaints, the exchange office contacted the correspondent exchange university directly. Some universities asked whether they could comment on the journals of astonishment. We acceded to this 
request but we also requested that the universities offered constructive feedback and also uses the first-person-(plural)-perspective in order to avoid ongoing accusations and counter-accusations. The comments posted were very constructive and most of them proposed useful alternatives to the criticised issues.

We recommended to the medical faculty that all exchange students visiting our university ought to write a journal of astonishment also. We propose that their journals are then posted to the exchange website on equal terms. This means that they will have an immediate acknowledgement on their internship certificate that they have participated in this quality circle. Moreover, the access to their journal of astonishment is also delayed for 6 months upon closure of the internship. We hope that these comments can serve as valuable feedback in order to make our faculty more attractive to foreign students.

The $100 €$ deposit request was the most widely discussed issue regarding this project. Due to some unfortunate experience at the beginning of this project we felt we had to impose this measure. Students and lecturers complained about the distrust this implies. Moreover, particularly prior to going abroad, some students protested that they were not able to deposit such an amount of money. However, this project is dependent on high return rates. A solution to this dilemma was the waiver of the deposit, when a faculty warrantor was designated.

\section{Conclusion}

All three approaches (paper report, web-based report, "journal of astonishmentblog") were appreciated by our students and helped to decrease non-illness related drop out rates.

The "journal of astonishment" pilot blog was the most appreciated approach. The "journal of astonishment" especially helped our students select and prepare for an exchange at a particular academic institution. Moreover, the interactive web-based platform can provide spontaneous help with the handling of problems. This blog is a rather low-cost tool which enhances student and host academic institution satisfaction. However, prior to installing this tool sufficient funding and proper maintenance needs to be provided. A deposit or a faculty warrantor proved to be beneficial to encourage all exchange students to post their journals. In order to provide enough blogs and bloggers we suggest that a joint-blog of several universities or a nationwide one be set up.

\section{Note}

1. Mahara open source eportfolio at http://Mahara.org/ last accessed 20/06/2012.

\section{References}

Byram, M. (2008) 'The 'Value' of academic mobility', in Students, Staff and Academic Mobility in Higher Education, eds M. Byram \& F. Dervin, Cambridge Scholars Press, Newcastle, pp. 31-47.

Develotte, C. (2006) 'Le Journal d'étonnement', Lidil, 34 [online] Available at: http://lidil. revues.org/index $25 . \mathrm{html}$

Hall, P., et al. (2012) 'Developing a sustainable electronic portfolio (ePortfolio) program that fosters reflective practice and incorporates CanMEDS competencies into the undergraduate medical curriculum', Academic Medicine, vol. 87, pp. 744-751.

Hanson, K. (2011) 'Blog enabled peer-to-peer learning', Dental Hygiene, vol. 85, pp. 6-12. 
Murphy, E. (2011) Mahara 1.4 Cookbook, Packt Publishing, Birmingham.

Murphy-Lejeune, E. (2008) 'The student experience of mobility, a contrasting score', in Students, Staff and Academic Mobility in Higher Education, eds M. Byram \& F. Dervin, Cambridge Scholars Press, Newcastle, pp. 12-30.

Reinhardt, C. (2009) 'Pour une application des trois compétences du CECR en classe', Le Français dans le monde, vol. 45, pp. 45-53.

Stefani, L., Mason, R. \& Pegler, C. (2007) The Educational Potential of E-Portfolios: Supporting Personal Development and Reflective Learning (Connecting with E-Learning), Routledge Chapman \& Hall, New York.

Wetmore, A. O., Boyd, L. D., Bowen, D. M. \& Pattillo, R. E. (2010) 'Reflective blogs in clinical education to promote critical thinking in dental hygiene students', Dental Education, vol. 74, pp. 1337-1350. 